\title{
REALIZATION OF BIOPRODUCTS AND SUSTAINABLE FOOD CHAIN IN BULGARIA
}

\author{
N. Kostadinova*, G. Aleksiev \\ Faculty of Economics, Trakia University, Stara Zagora, Bulgaria
}

\begin{abstract}
Consumption of organic products has grown in recent years, their demand is increasing, and the organic market is one of the world's fastest growing ones. The factors influencing the realization and competitiveness of bio-products, the sustainability of their supply and consumption have not only an economic but also a social and ecological importance.

The aim of the present study is to examine the realization of bioproducts in the conditions of sustainable functioning of the food supply chain in Bulgaria. To achieve this goal, the following tasks are solved: to identify the specificities of the functioning of the market of organic products and their consumption; to revel the relationship in separate phases of bio-food chain and on this basis to make recommendations for the development of organic farming in Bulgaria. The methods used are analysis and synthesis, induction and deduction, systematic and synergetic approach, statistical calculations to solve the task and achieve the goal of the study.

Expectations from the survey are optimistic in view of the increase in production.
\end{abstract}

Key words: sustainability, organic farming, organic food, market, consumption

\section{INTRODUCTION}

Consumption of organic products has grown in recent years, their demand is increasing, and the organic market is one of the world's fastest growing ones. The factors influencing the realization and competitiveness of bioproducts, the sustainability of their supply and consumption have not only an economic but also a social and ecological importance.

The aim of the present study is to examine the realization of bioproducts in the conditions of sustainable functioning of the food supply chain in Bulgaria. To achieve this goal, the following tasks are solved: to identify the specificities of the functioning of the market of organic products and their consumption; to revel the relationship in separate phases of biofood chain and on this basis to make recommendations for the development of organic farming in Bulgaria. The methods used are analysis and synthesis, induction and deduction, systematic and synergetic approach,

\footnotetext{
*Correspondence to: Nadka Kostadinova, Faculty of Economics, Trakia University, Stara Zagora 6000,Bulgaria,nadya_kostadinova@yahoo.com
}

statistical calculations to solve the task and achieve the goal of the study.

\section{REALIZATION OF ORGANIC PRODUCTS IN BULGARIA}

The improved economic situation in the country and the increase in the average incomes in 2014 - 2015 stimulate the increasing interest in the popular habits for healthy eating and lead to increased consumption of organic foods. Current market trends can be summarized as the market breakthrough in 2014-2015 was that it included not only the highest income households seeking high quality products, but also the middle-income earners who are trying to follow a healthy lifestyle and are concerned about unhealthy additives or preservatives in traditional products available on the market.

The concept of healthy living and buying organic food has crossed the boundaries of big cities. A growing group of users is also reported in large and medium-sized cities. Although buyers in major cities dominate, the penetration of regional and local markets has begun. All types of retail channels register an 
increase in sales of organic products. Improved consumer demand encourages retailers to pay more attention to organic products. The share of organic sales through this channel increased from $44.5 \%$ in 2010 to $61.4 \%$ in 2016 . This helps to increase consumer awareness, especially regarding labeling. All retail chains already have dedicated organic food venues, and some market players are making special efforts to highlight those sales by improving the diversity of organic food available.

The main challenge remains the level of consumer income. Organic foods often come at higher than their conventional counterparts' price and are considered inaccessible to many. Higher prices for organic products are a barrier to faster market penetration and rapid sales growth. Consumer awareness of organic foods is still not very high but remains critical to market developments. Often, conventional food equivalents may have brands or subtypes that are labeled "local" or "natural" product and attract lower cost customers than the equivalent bio product. Such "eco / local / clean" labeling often misleads users who rarely distinguish between labels. Advertising and marketing campaigns continue to shape positive consumer sentiment.

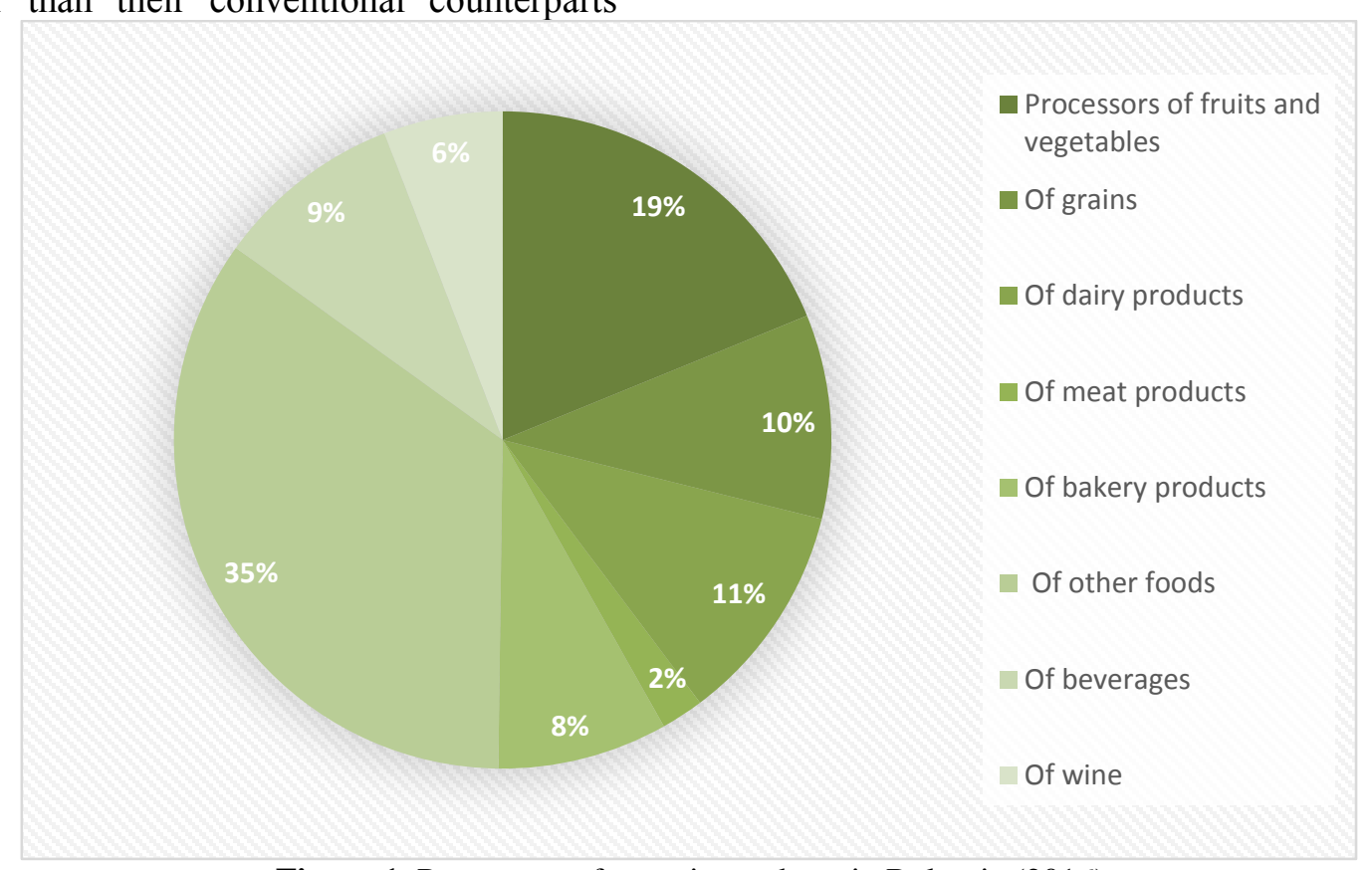

Source: Euromonitor

Figure 1. Processors of organic products in Bulgaria (2016)

Factors that contribute to consumer redundancy for organic products are weaknesses in the certification system and lack of trust in their labels. Progress in this regard was made in 2016 with the improvement of the regulatory environment and supervision, which promises better prospects for the future.

Organic food sales were estimated in 2015 at BGN 30 million (US \$ 17 million), up 7\% from 2014 (Euromonitor). The growth over the last 5 years (2015 compared to 2010) was impressive $-73 \%$. The sales estimate for 2016 is about BGN 31.6 million (USD 17.5 million) or $5.3 \%$ more than in 2015 and may reach BGN 33.3 million (USD 18.5 million). E.) in 2017 (final data for 2017 are not yet available) Estimated levels of sales of organic products in Bulgaria in 2020 amounting to over 39 million. This would represent an increase of $30 \%$ (2015-2020).
Organic beverages are an emerging category of organic products. Their prices are high, often exceeding their conventional equivalents by $300-500 \%$. Organic coffee, cocoa and energy drinks are the most common on the market. Consumers are not very familiar with organic drinks. They are often looking for healthier lifestyles and prefer to buy freshly squeezed juices with reduced sugar content and low calorie or water minerals, and therefore sales are unlikely to develop quickly in the future without further marketing efforts.

Rapid sales are expected for organic dairy, bee, wine and pasta sales. These products are sourced from both local manufacturers and importers, allowing for greater competition, diversity, brand differentiation and promotion. The trend of expanding purchases of fresh fruits and vegetables will continue to develop. 


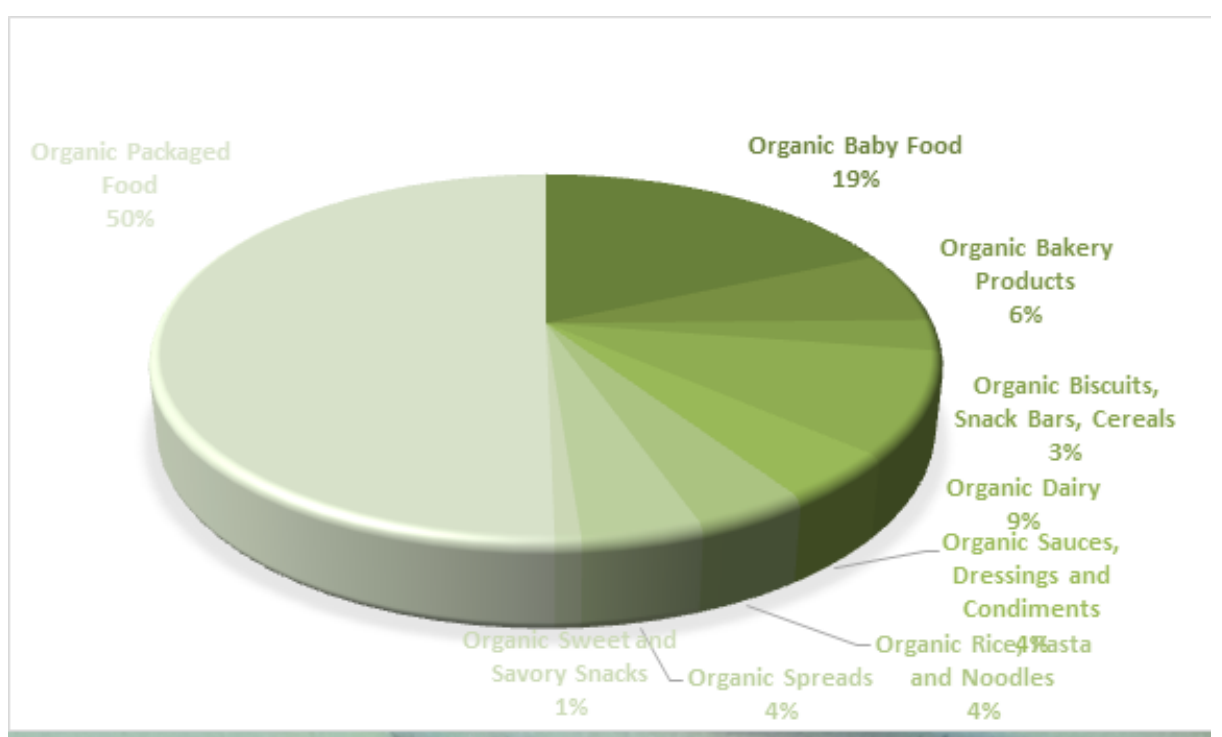

Figure 2. Organic foods consumption in Bulgaria (2016)

Source: Euromonitor

There are optimistic future prospects for higher sales of more processed organic products that build on the already popular basic organic products. For example, the dairy category is likely to have more sales of dairy desserts or ice cream in addition to established yogurt and cheese; pastry is likely to be added to pastries. Diversity becomes extremely important and suppliers are likely to offer new products.

The top five organic food companies accounted for $54 \%$ of sales in 2015. The market is fragmented, and the remaining players are small companies with less than $1 \%$ market share. This is not favorable for demand as there is no price competition on the market and higher prices are maintained.

\section{CONCLUSION}

Bulgarian organic market is still developing rapidly. Bulgarian producers are yet to adept to the local market trends, as they are focused primarily on maximizing production and export. As evident by the alterations in the two presented figures - the processing and market consumption there are no connections between what is being produced and what is demanded on the local market. This leave the local consumers reaching for imported products, all the while Bulgarian producers are struggling to find a marketplace in Europa and North America.

In order to improve the position of the local production and processing of organic foods and furthermore their realization a consolidation of the efforts through the whole value chain is needed. There are some operational organic organization for producers and processors, but they are really communicating and setting common goals.
The levels of social support for this important sector can also be improved in order to achieve the previously set goals. In latter year the level of social support for the sector have rapidly declined after most of fund provided by CAP have depleted.

\section{REFERENCES}

1. Balieva, G. N., M. Huliyan (2015). Production and supply of regional food products - incentives and challenges for the small holdings in Bulgaria. International Journal of Science and Research, Online ISSN 2319-7064, Volume 4, Issue 2 February 2015, 576-580. (Available at: http://www.ijsr.net/archive/v4i2/v4i2_01.php \#sthash.ablyMD1V.dpbs )

2. Eurostat: Farm Structure Survey data (holdings, la-bour use, age and sex of farm managers, education and vocational training): http://epp.eurostat.ec.europa.eu/portal/page/p ortal/statistics/search_database V/Eurostat: data on the organic sector (area, crop and animal products, operators): http://epp.eurostat.ec.europa. eu/portal/page/portal/statistics/search_databas e

3. FiBL and IFOAM, 2015, The world of organic agriculture, Statistics and emerging trends,

https://www.fibl.org/fileadmin/documents/sho p/1663-organic-world-2015.pdf

4. Gonzalvez,V.,0. Schmid, H.Willer.2011. Organic Action Plans in Europe in 2011. In: Wilier, H. and Kilcher, L. eds.

5. Euromonitor, 2018, http://www.euromonitor.com/organicpackaged-food-in-bulgaria/report

6. Eurostat Database 